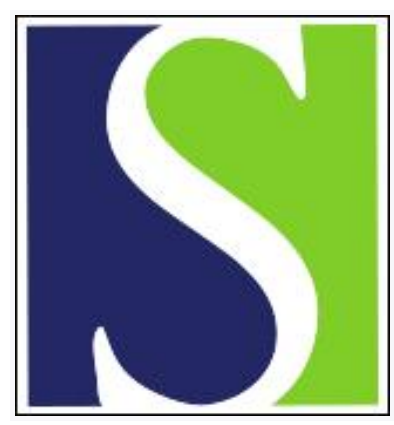

Scand J Work Environ Health 2005;31(4):286-290

https://doi.org/10.5271/sjweh.884

Issue date: Aug 2005

\title{
Effect of impulse vibration on red blood cells in vitro
}

by Ando H, Nieminen K, Toppila E, Starck J, Ishitake T

Affiliation: Department of Environmental Medicine, Kurume University School of Medicine, 67 Asahi-machi, Kurume 830-0011 Japan. hando@med.kurume-u.ac.jp

Key terms: hand-arm vibration; hemolysis; impulse vibration; impulsiveness; in vitro; peak acceleration; red blood cell; vibration-induced white finger

This article in PubMed: www.ncbi.nlm.nih.gov/pubmed/16161711

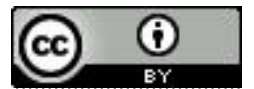




\title{
Effect of impulse vibration on red blood cells in vitro
}

\author{
by Hideo Ando, MD, ${ }^{1,2}$ Kalevi Nieminen, ${ }^{1}$ Esko Toppila, PhD, ${ }^{1}$ Jukka Starck, PhD, ${ }^{1}$ Tatsuya Ishitake, MD²
}

\begin{abstract}
Ando H, Nieminen K, Toppila E, Starck J, Ishitake T. Effect of impulse vibration on red blood cells in vitro. Scand J Work Environ Health 2005;31(4):286-290.
\end{abstract}

Objectives This study was carried out to evaluate the damage induced in red blood cells by exposure to impulse vibration.

Methods The peak accelerations of impulse vibration included 50,100, 200, 250 and $300 \times 10^{3} \mathrm{~km} / \mathrm{s}^{2}$. A blood sample was put in a container filled with heparin so that there was no space inside. For each peak acceleration the exposure durations of 10, 20, and 30 minutes were used. The repetition rate of the impulses was 1 cycle per second (1 cycle/s). After the vibration exposure, the percentage of damaged red blood cells was calculated. Then the red blood cells were studied microscopically.

Results Each vibration caused damage to red blood cells with all durations. The higher the peak acceleration and the longer the exposure duration, the more the damage to the red blood cells. Of the five impulse vibration levels with the three exposure durations, the largest damage was done by the vibration exposure with a peak acceleration of $300 \mathrm{~km} / \mathrm{s}^{2}$ for 30 minutes with a mean value of $76.7 \%$ for the damaged cells, followed by the exposure with a peak acceleration of $300 \mathrm{~km} / \mathrm{s}^{2}$ for 20 minutes with $55.5 \%$ of the cells being damaged. For exposure for 20 and 30 minutes, the vibration with peak accelerations of higher than $200 \mathrm{~km} / \mathrm{s}^{2}$ provoked damage to red blood cells out of proportion to those with peak accelerations lower than $200 \mathrm{~km} / \mathrm{s}^{2}$.

Conclusions Impulse vibration was shown in vitro to cause damage to red blood cells. It is suggested that the damage of red blood cells depends on both the peak acceleration and exposure duration of impulse vibration.

Key terms hand-arm vibration, hemolysis, impulsiveness, peak acceleration, vibration-induced white finger.

The fragmentation of red blood cells can be seen when they are exposed to excessive mechanical stress in circulation. It is known that hemolysis occurs when a part of the body is exposed to intense impulses repeatedly in such activities as marathons (1), karate (2), and conga drum playing (3). It is suggested that hemolysis takes place through the pressure applied from outside on blood vessels when hands and feet are hit directly on solid objects (4).

On the other hand, impulse vibration can be found in some vibratory tools, such as impact wrenches and chipping hammers. The workers using percussion vibratory tools are often exposed to impulse vibration directly on their hands and palms (5). An association between hand-arm vibration syndrome and exposure to impulse vibration is now recognized for workers who occupationally use handheld power tools (6). Thus the importance of impulsiveness is emphasized with regard to the effects of vibratory tools on their users. However, no studies, as far as we know, have been conducted concerning the pathological effects, such as hemolysis, of impulse vibration on the circulatory system.

Our question is whether workers suffer from intravascular hemolysis due to their use of vibratory tools, as athletes do. As the first step, we investigated the effect of impulse vibration on the damage of red blood cells in vitro. In this study, we evaluated the peak acceleration and exposure duration of impulse vibration, the levels of which caused the breakdown of red blood cells.

\section{Materials and methods}

\section{Equipment}

A block diagram of the vibration generator and analyzing equipment used in this study is shown in figure 1. A vibration signal was sent to a linear motor through a controller (LinMot E-2000-AT, LinMot, Zurich, Switzerland). The motor moved and hit a rotor weighing

1 Department of Physics, Finnish Institute of Occupational Health, Helsinki, Finland.

2 Department of Environmental Medicine, Kurume University School of Medicine, Kurume, Japan.

Reprint requests to: Dr Hideo Ando, Department of Environmental Medicine, Kurume University School of Medicine, 67 Asahi-machi, Kurume 830-0011 Japan. [E-mail: hando@med.kurume-u.ac.jp] 


\section{IMPACT HAMMER SIMULATOR}

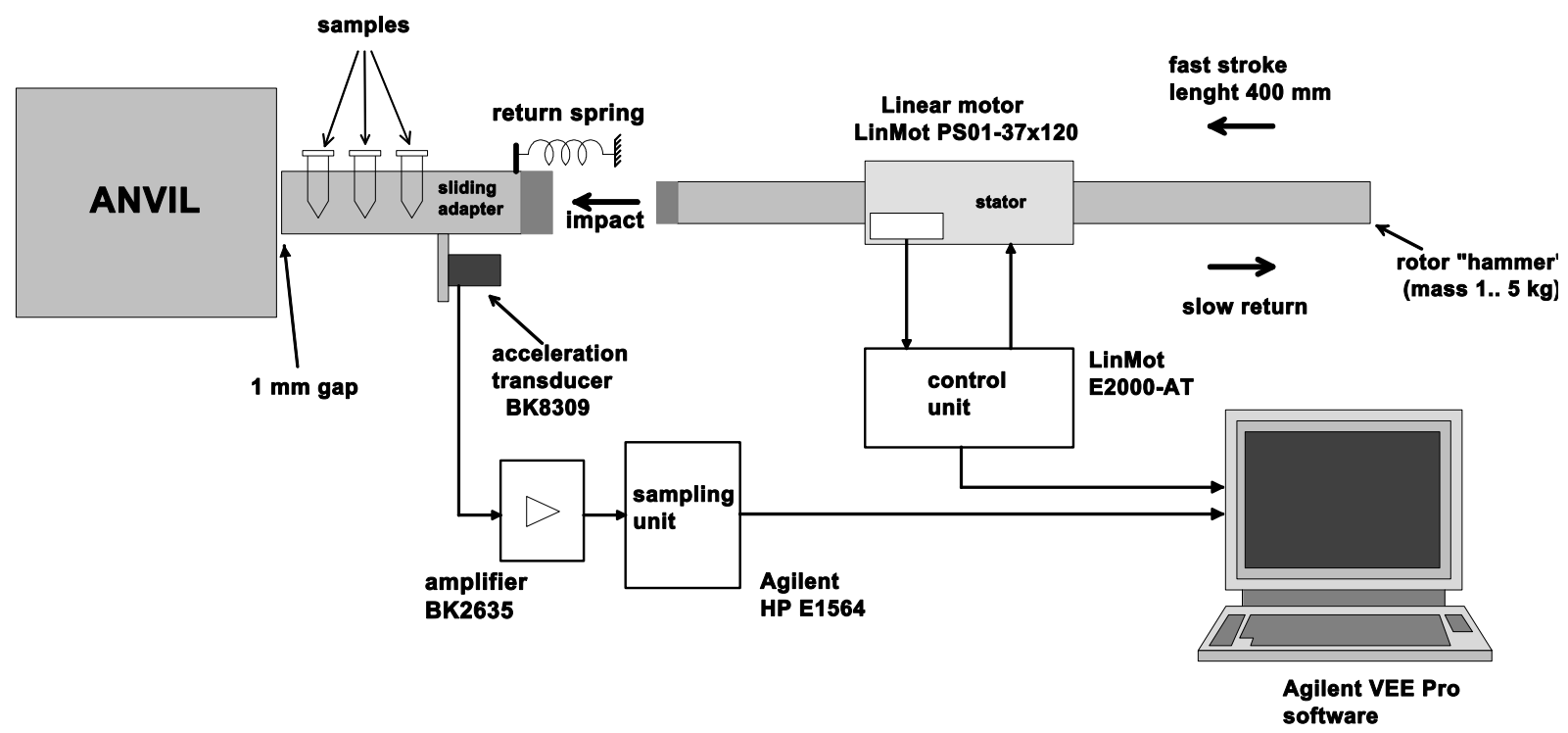

Figure 1. Block diagram of the vibration generating and measurement system.

1.5 kilograms with a stroke length of 400 millimeters against an adaptor that faced an anvil with a 1-millimeter gap between them. Thus three blood samples in the adaptor were exposed to impulse vibration at the same time at a repetitive rate of 1 cycle per second (1 cycle/ s). The acceleration of impulse vibration was measured at the adaptor by an acceleration transducer (B\&K 8309, Brüel \& Kjær, Naerum, Denmark), amplified by a charge amplifier (B\&K 2635, Brüel \& Kjær) and recorded by a sampling unit (Agilent HP E1564, Agilent Technologies, Palo Alto, CA, USA). Figure 2a shows a photograph of the vibration generator, custom made by the Finnish Institute of Occupational Health.

\section{Experimental procedure}

Ten milliliters of blood was collected from an antecubital vein of a healthy 36-year-old man through a $20-\mathrm{G}$ needle into a syringe containing EDTA (ethylenediaminetetraacetic acid); $0.6 \mathrm{ml}$ was transferred into a polystyrene tube coated with heparin. This blood sample was put into the tube in a way that left no space inside. The red blood cell count for control was conducted by a blood cell analyzer (COULTER ${ }^{\circledR}$ A.T Series Analyzer, Coulter Corporation, Miami, FL, USA) before vibration was applied. The tube was immediately put into the special machine that generated impulse vibration (figure $2 b$ ).

The five peak accelerations of impulse vibration that we used included 50,100, 200, 250, and $300 \mathrm{~km} / \mathrm{s}^{2}$ (figure 3 ). In all of the trials a repetition rate of $1 \mathrm{cycle} / \mathrm{s}$ was used. For each peak acceleration, the test was performed with three durations (ie, 10, 20, and 30 minutes). After the vibration exposure, a new red blood cell count was taken. Thereafter the percentage of damaged red blood cells was calculated. Red blood cells exposed to each impulse vibration were examined microscopically
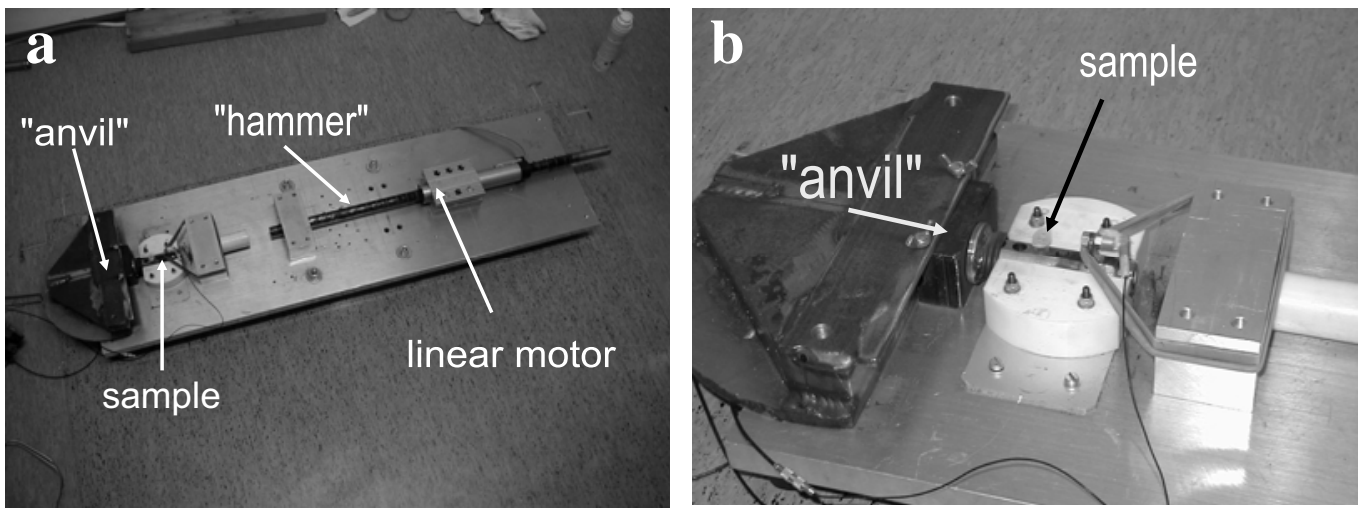

Figure 2. Photos of the vibration generator system. General view (a) and detailed view (b) with a blood sample mounting. 


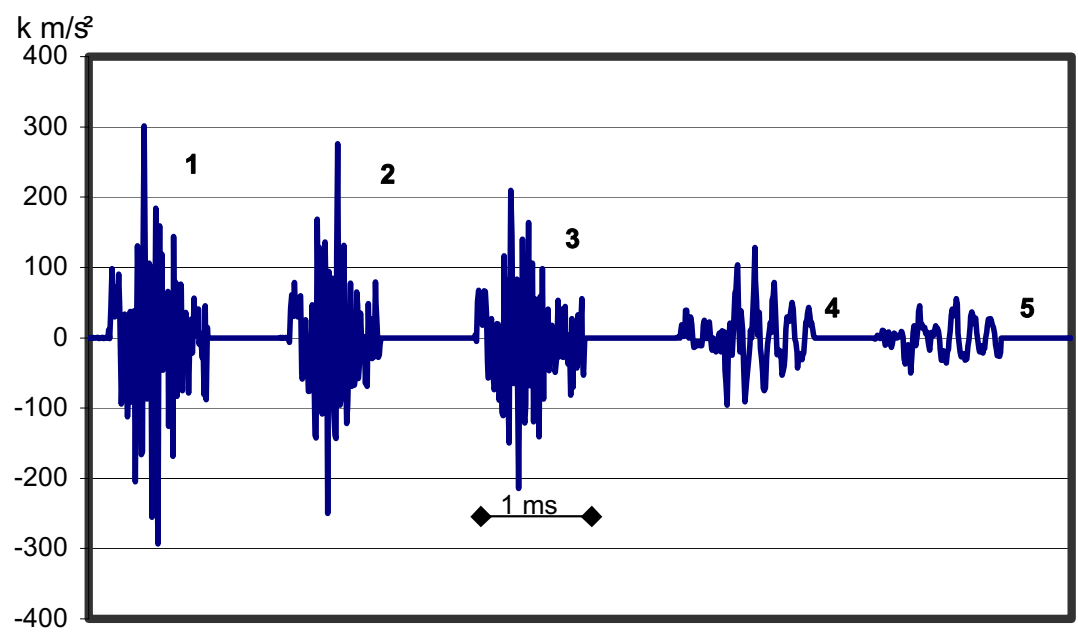

Figure 3. Time functions of the single impulses used in the study. Peak acceleration levels of $300 \mathrm{~km} / \mathrm{s}^{2}(1), 250 \mathrm{~km} / \mathrm{s}^{2}(2), 200$ $\mathrm{km} / \mathrm{s}^{2}(3), 100 \mathrm{~km} / \mathrm{s}^{2}(4)$, and $50 \mathrm{~km} / \mathrm{s}^{2}(5)$ are illustrated.

(Eclipse E800, Nikon, Melville, NY, USA) for a morphological study. The experiment was conducted seven times.

\section{Statistical analysis}

A repeated-measures analysis of variance (ANOVA) was used to evaluate the difference in the percentage of damage across the five peak accelerations and three durations of impulse vibration. When a significant difference was found, a multiple comparison test (Bonferroni test) was used to compare the different conditions. A P-value of 0.05 was set as the limit of the statistical significance.

\section{Results}

Before the vibration exposure, the red blood cell count ranged from 496 to $527 \times 10^{6} /$, within the normal range of a healthy male subject in our laboratory (400 to $\left.530 \times 10^{6} / 1\right)$.

All impulse vibration used in the study caused damage to red blood cells. The higher the peak acceleration and the longer the exposure duration, the more damage done to the red blood cells (figure 4). The effects of both the peak acceleration and the exposure duration, as well as their interaction, were found to be significant with respect to the damage done to red blood cells. The repeated-measures ANOVA indicated a significant difference in the damage to red blood cells for the five peak accelerations $(\mathrm{F}=25.8, \mathrm{P}<0.0001)$. A multiple comparison test (Bonferroni test) showed that the damage produced by impulse vibration with a peak acceleration of $300 \mathrm{~km} / \mathrm{s}^{2}$ was the greatest, followed by vibration at $250 \mathrm{~km} / \mathrm{s}^{2}$ and then that of $200 \mathrm{~km} / \mathrm{s}^{2}$. The repeatedmeasures ANOVA also indicated a significant difference in the damage to red blood cells for the three

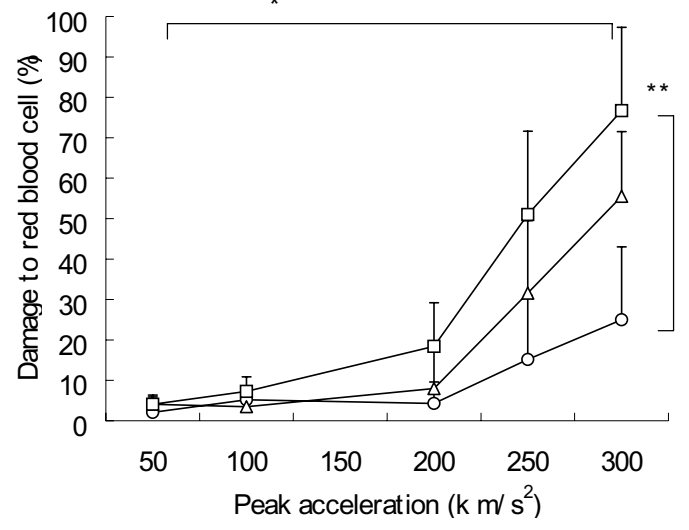

Figure 4. Means and standard deviations of the damage of red blood cells caused by impulse vibration for three exposure durations. (circle, triangle, and square $=$ exposure duration of 10,20 and 30 minutes, respectively; ${ }^{*} \mathrm{P}<0.0001$, among five peak accelerations; ${ }^{* *} \mathrm{P}<0.0001$, among three exposure durations).

vibration durations ( $\mathrm{F}=88.8, \mathrm{P}<0.0001)$. The Bonferroni test showed that the damage induced during 30 minutes of vibration exposure was the greatest, followed by that during 20 minutes $(\mathrm{P}<0.0001)$. The damage by impulse vibration during 10 minutes of exposure was the smallest. Moreover, an interaction was found between peak acceleration and duration with respect to the damage done to red blood cells $(\mathrm{F}=19.8, \mathrm{P}<0.0001)$. Of the five acceleration levels with three exposure durations, the greatest damage occurred in the vibration exposure with a peak acceleration of $300 \mathrm{~km} / \mathrm{s}^{2}$ for 30 minutes with a mean value of $76.7 \%$ for damaged cells, followed by the exposure with $300 \mathrm{~km} / \mathrm{s}^{2}$ for 20 minutes with $55.5 \%$ of the cells damaged.

Figure 5 shows typical photomicrographs of peripheral blood smears. No fragmentation of red blood cells was detected before the exposure to impulse vibration (control, figure 5a). Some fragmentations of the red blood cells, in contrast, were observed after exposure to all of the acceleration levels studied (figure 5b). 

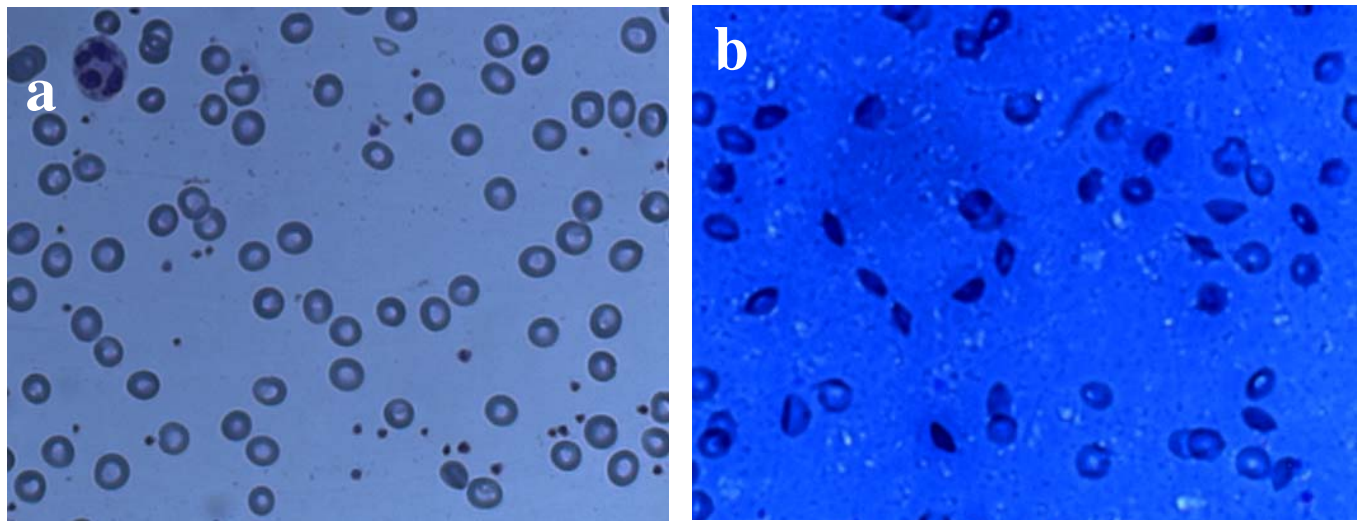

Figure 5. Typical photographs of a peripheral blood smear before (a) and after (b) exposure to impulse vibration with a peak acceleration of $300 \mathrm{~km} / \mathrm{s}^{2}$ for 30 minutes.

\section{Discussion}

Percussion tools in general have been considered to involve various pathological features, such as vibrationinduced white finger, hypothenar hammer syndrome, and noise-induced hearing loss. A high prevalence of vibration-induced white finger has been found among workers exposed to impulse vibration from, for example, pedestal grinding (7) and riveting hammers (8). In an epidemiologic cross-sectional study with pneumatic hammers and pedestal grinding, the impulse character of vibration was observed to increase the risk of vibration-induced white finger $(9,10)$. It has been suggested that shear stress arterially is provoked by impulse vibration and that it contributes to circulatory disorders (11). In addition, hypothenar hammer syndrome, in which stenosis or occlusion can be detected in the ulnar artery at the hypothenar part of the hand, has been observed to occur among workers using percussion tools such as impact wrenches and chipping hammers (12). Repetitive blunt trauma in the palm originating from vibratory tools is suggested to result in the syndrome. In addition, percussion vibratory tools produce impulse noise as well. Impulse noise has been considered to be more likely to cause noise-induced hearing loss than steady state noise is (13). Thus, when the effect of vibration on workers is under consideration, it is important to emphasize the impulsiveness of hand-transmitted vibratory tools (14). As far as we know, the aforementioned pathologies are the only ones reported with respect to the influence of impulse vibration on workers. Thus the association between impulse vibration and workers' health should be studied in relation to other organs as well. In our study, as a first step, we evaluated the effect of impulse vibration on the circulatory system in vitro, especially that on red blood cells.

Impulse vibration was shown to cause damage to red blood cells in vitro. The peripheral blood smears clearly showed some schistocytes or fragmentations of red blood cells after exposure to impulse vibration. The damage seems to depend on the combined effect of peak acceleration and exposure duration. The greater and the longer the exposure to impulse vibration, the more damage caused to red blood cells. This finding suggests a synergistic effect on red blood cells related to the peak acceleration and exposure duration of impulse vibration. It was also found that the damage induced by exposure to impulse vibration was provoked in a logical way at peak accelerations of $\geq 200 \mathrm{~km} / \mathrm{s}^{2}$. This finding suggests that there is a critical point in peak acceleration at which red blood cells start to break down.

Clinically, the red cell fragmentation syndrome is known to occur when a part of the body is repeatedly exposed to intense mechanical impulses (15). Red blood cells are thought to be destroyed by the pressure applied on blood vessels from outside. Examples for the pathology include activities such as karate, marathon running, and conga drum playing. During these activities, the hands and feet are hit repeatedly against the ground or hard objects. As a result, intravascular hemolysis is thought to occur. Telford et al (16) have recently shown that foot strikes are the major contributor to hemolysis during running. In some workplaces, likewise, workers often hit their hands and palms repeatedly against hard objects via hand-transmitted vibratory tools. In such conditions it is possible that workers, even with their gloves on, could develop the same pathology in their hands, as that observed in marathon runners or karate experts.

One limitation of this study is that the response of the red blood cells in vitro may differ from that in vivo. When hands are actually exposed repeatedly to intense impulses, the impulse would be absorbed to some degree in the tissues at the hands or wrists because of their elastic character so that the damage to red blood cells would be modified. A significantly higher quantity of transmission and absorption of mechanical energy into the hand was shown during exposure to impulse vibration 
when compared with nonimpulse vibration (17). In addition, in the transmission of vibration from the handle of the tool, hand-grip forces have been shown to play an important role. The higher grip forces cause more effective transmission, especially in the case of impulse vibration with high-frequency components, which result in a more-profound effect on the hand-arm system (18). In addition, the experimental procedure could not reflect the circulation of red blood cells in vivo. Certain red blood cells are exposed for a very short period to impulse vibration. After 8 hours of work, however, workers have been exposed to a considerable amount of impulse vibration. Although our results do not exactly reflect actual work conditions, attention should still be drawn to the findings on the effect of impulse vibration.

Transient analyses of impulse vibration show that short peaks occurred at intervals of 1 second. We studied considerably high peak accelerations. However, in general, percussion tools, such as riveting and chipping hammers, generate magnitudes up to as high as $100 \mathrm{~km} / \mathrm{s}^{2}$. In fact, an acceleration of $200 \mathrm{~km} / \mathrm{s}^{2}$ has been observed for riveting tools (19). It should be noted that, in our study, the damage induced in red blood cells by impulse vibration with peak accelerations in excess of $200 \mathrm{~km} / \mathrm{s}^{2}$ was out of proportion to those lower than $200 \mathrm{~km} / \mathrm{s}^{2}$. As far as we know, no epidemiologic studies have been conducted regarding hemolysis or hemoglobinuria in workers occupationally exposed to impulse vibration. Our study suggests a need for hematological investigations of workers using impulse vibratory tools.

In conclusion, it can be said that this study shows that impulse vibration causes damage to red blood cells in vitro, and this damage seems to depend on both the level of peak acceleration and the exposure duration of the impulse vibration. A critical peak acceleration for impulse vibration was also suggested with respect to the destruction of red blood cells.

\section{Acknowledgments}

We would like to thank Ms Outi Tupasela and Ms Sirkka Hopeakangas, Department of Clinical Laboratory, Finnish Institute of Occupational Health, for their assistance in handling the blood samples. We are also grateful to Ms Tuula Stjernvall, Department of Pathology, Finnish Institute of Occupational Health, for her assistance in conducting the microscopic examination.

\section{References}

1. Buckle RM. Exertional (march) haemoglobinuria: reduction of haemolytic episodes by use of sorbo-rubber insoles in shoes. Lancet 1965;1:1136-8.

2. Streeton JA. Traumatic haemoglobinuria caused by karate exercises. Lancet 1967;2:191-2.

3. Kaden WS. Traumatic haemoglobinuria in conga drum players. Lancet 1970;1:1341-2.

4. Davidson RJL. Exertional haemoglobinuria: a report on three cases with studies on the haemolytic mechanism. J Clin Pathol 1964;17:536-40.

5. Pelmear PL, Wills M. Impact vibration and hand-arm vibration syndrome. J Occup Environ Med 1997;39:1092-6.

6. Pelmear PL, Kusiak R, Leong D. Hand-arm vibration syndrome associated with impact vibration. J Low Freq Noise Vibr 1995;2:73-9.

7. Starck J, Färkkilä M, Aatola S, Pyykkö I, Korhonen O. Vibration syndrome and vibration in pedestal grinding. Br J Ind Med 1983;40:426-33.

8. Engström K, Dandanell R. Exposure conditions and Raynaud's phenomenon among riveters in the aircraft industry. Scand J Work Environ Health 1986;12:293-5.

9. Starck J. High impulse acceleration levels in hand-held vibratory tools: an additional factor in the hazards associated with the hand-arm vibration syndrome. Scand J Work Environ Health 1984;10:171-8.

10. Starck J, Pyykkö I. Impulsiveness of vibration as an additional factor in the hazards associated with hand-arm vibration. Scand J work Environ Health 1986;12:323-6.

11. Nerem RM. Vibration-induced arterial shear stress: the relationship to Raynaud's phenomenon. Arch Environ Health 1973;26:105-10.

12. Kaji H, Honma H, Usui M, Yasuno Y, Saito K. Hypothenar hammer syndrome in workers occupationally exposed to vibrating tools. J Hand Surg 1993;18B:761-6.

13. Starck J, Pekkarinen J, Pyykkö I. Impulse noise and hand-arm vibration in relation to sensory neural hearing loss. Scand J Work Environ Health 1988;14:265-71.

14. Starck J, Pekkarinen J, Pyykkö I. Physical characteristics of vibration in relation to vibration-induced white finger. Am Ind Hyg Assoc J 1990;51:179-84.

15. Foerster J. Red cell fragmentation syndromes. In: Lee GR, Foerster J, Lukens J, Paraskevas F, Greer JP, Rodgers GM, editors. Wintrobe's clinical hematology. 10th ed. Baltimore (MD): Williams \& Wilkins; 1999.

16. Telford RD, Sly GJ, Hahn AG, Cunningham RB, Bryant C, Smith JA. Footstrike is the major cause of hemolysis during running. J Appl Physiol 2003;94:38-42.

17. Burström L, Sörensson A. The influence of shock-type vibrations on the absorption of mechanical energy in the hand and arm. Int J Ind Erg 1999;23:585-94.

18. Starck J, Pekkarinen J, Chun LC. Transmission of vibration from tool handle to wrist and to head. Kurume Med J 1990;37 suppl:s1-s11.

19. Dandanell R, Engström K. Vibration from riveting tools in the frequency range $6 \mathrm{~Hz}-10 \mathrm{MHz}$ and Raynaud's phenomenon. Scand J work Environ Health 1986;12:338-42.

Received for publication: 17 May 2004 